\title{
Successes, Challenges and Opportunities Towards Universal Health Coverage for Maternal and Child Health in South East Asian Countries: A Systematic Review
}

Upuli Amaranganie Pushpakumari perera ( $\nabla$ tauapp100@gmail.com )

Ministry of Health, Sri Lanka; the University of Queensland, Australia https://orcid.org/0000-0003-31776920

Charles Gilks

The University of Queensland School of Public Health

\section{Yibeltal Alemu}

The University of Queensland School of Public Health

\section{Research}

Keywords: Universal health coverage, maternal care, childcare, Southeast Asia, challenge, Opportunity

Posted Date: September 22nd, 2020

DOI: https://doi.org/10.21203/rs.3.rs-78717/v1

License: (a) This work is licensed under a Creative Commons Attribution 4.0 International License. Read Full License 


\section{Abstract}

Background: Sustainable Development Goal 3 (SDG-3) aims to ensure healthy lives and promote wellbeing for all. Universal Health Coverage (UHC) assures delivering health services to all who need without suffering from financial hardships. This paper aims to identify the successes, challenges and opportunities towards achieving UHC for maternal and childcare in countries in the World Health Organization, South East Asian Region (SEAR).

Methods: We conducted a systematic review of the literature. We searched PubMed, Embase, Scopus, CINAHL, PsycINFO, WHO research portal and Google scholar for studies published in English from 2010 to 2020. We included studies conducted in maternal and childcare focusing on challenges, opportunities or successes towards UHC in countries in SEAR. Data was synthesized and presented as a narrative description, according to the Preferred Reporting Items for Systematic Reviews and Meta-Analyses (PRISMA) guidelines.

Results: We identified 62 studies with different study designs from eight SEAR countries , majority were from India. We observed successes or opportunities in access and quality in $\mathrm{MCH}$ with government cash transfer schemes and private sector contribution in India, Bangladesh and Indonesia. Politically prioritized $\mathrm{MCH}$ care was identified as an opportunity in a state of India.

Inadequate healthcare infrastructure including trained human resources, medical products and other supplies were identified as the main challenges in the region. Facilities are overcrowded in Bangladesh and Indonesia. From provider perspective, health care workers' knowledge and skills as well as attitudes and behaviors were also identified as issues in the region. Lack of health literacy, misconceptions and cultural barriers are identified as challenges from clients' side. Difficulties in geographical distribution and transport were contributing to poor healthcare access in four countries. Deficiencies in government policies and administration were identified in some fields. Poverty was detected as an overarching barrier.

Conclusions: SEAR countries have demonstrated improvements in access, quality and equity on $\mathrm{MCH}$ towards UHC. There are, however, challenges related to human and other resources, health care facilities and socioeconomic determinants of health. Regional bodies as well as authorities in individual countries should work on these issues to address challenges to achieve UHC.

Registration: PROSPERO: CRD42020166404

\section{Introduction}

The Sustainable Development Goals (SDGs) were adopted by all United Nations Member countries in 2015 as a universal action to end poverty, protect the planet and ensure that all people enjoy peace and prosperity by 2030. There are 17 integrated goals that action in one area will affect outcomes in others ${ }^{1}$. The third Sustainable Development Goal (SDG-3) aims to ensure healthy lives and promote well-being for all at all ages $^{1}$. It has a target to reduce neonatal mortality to at least 12 per 1000 live births, under-5 mortality to 25 per 1000 live births and maternal mortality ratio to a global level of 70 per 100000 live births by $2030^{2}$. Target 3.8 focuses on achieving universal health coverage (UHC), including financial risk protection, access to quality 
essential health-care services and access to safe, effective, quality and affordable essential medicines and vaccines for all ${ }^{1}$.

Universal health coverage is a broad concept in which all individuals and communities receive the health services they need without suffering financial hardship ${ }^{3}$. It includes the full spectrum of essential, quality health services, from health promotion to prevention, treatment, rehabilitation, and palliative care ${ }^{4}$. The definition of UHC expressed three related objectives namely equity in access to health services, good quality of health services and protection against financial risk ${ }^{5}$.

The World Health Organization has developed an index to monitor the status of implementation of UHC. The $\mathrm{UHC}$ services coverage index $(\mathrm{UHCl})$ is calculated as the geometric mean of the coverage of essential services based on 17 tracer indicators from the following categories: (i) reproductive, maternal, newborn and child health, (ii) infectious diseases, (iii) non-communicable diseases and (iv) service capacity and access and health security. The $\mathrm{UHCl}$ is reported on a unit-less scale of 0 to $100^{6}$.

Almost all countries are making progress towards UHC with different intensities. In middle- and low-income countries, the progress is slow 4 . Improvements in the index were seen in all WHO regions with European, Western Pacific and the America Regions have reached to almost $80 \%$ coverage in 2017 . WHO Western Pacific Region had the largest improvement over the specified period. With minor variations between member countries, SEAR coverage has reached near $60 \%$ in $2017^{7}$.

More than a quarter of the world population lives in WHO South-East Asia Region, one of the six regions consisting 11 countries. The region has number of priority programmes aligned to SDGs, including $\mathrm{UHC}^{2,8}$. The region shows tremendous achievements in under-five, neonatal mortality and maternal mortality ${ }^{2}$. According to WHO progress reviews, at the current rate of progress, the SEAR is likely to achieve the SDG target of underfive mortality reduction. However, for achieving the targets of neonatal mortality and maternal mortality, countries need significant acceleration of actions ${ }^{2}$. The region also faces many challenges in providing high quality medical services without financial burden to the population. Around 800 million people in this region lack the access to essential health services; over 65 million disadvantage due to out of pocket expenditure ${ }^{2,9}$. Region specific challenges and opportunities may exist towards achieving UHC and other health-related SDG targets. Achieving UHC depends on the capacity of the building blocks of the health system. It is thus essential that countries strengthen their health systems, including healthcare financing, health workforce, governance, health information system, procurement and supply of medicines and health technologies, health information system and service delivery ${ }^{4}$.

As far as our knowledge is concerned, there is no systematically synthesised evidence on the successes and challenges, related to health systems, towards achieving UHC for maternal and child health $(\mathrm{MCH})$ services in the region. The objective of this review is to identify successes, challenges and opportunities towards achieving $\mathrm{UHC}$ for $\mathrm{MCH}$ care in SEAR countries. Our review will potentially contribute in the regional effort to achieve $\mathrm{UHC}$ in relation to $\mathrm{MCH}$.

\section{Methodology}


A systematic review was conducted and reported in accordance with the preferred reporting items for Systematic reviews and Meta-Analyses criteria (PRISMA) ${ }^{10}$. (See checklist in Additional file 01). In accordance with PRISMA guidelines, the systematic review was registered with the International Prospective Register of Systematic Reviews (PROSPERO) on $10^{\text {th }}$ of July 2020. (Registration number: CRD42020166404).

\section{Search Strategy}

The search strategy was developed to fulfill objectives and characterized them in terms of the four elements [Population, Intervention, Comparison, and Outcomes (PICO)]. Search terms included the terms for all components of UHC, SEAR countries, similar terms for $\mathrm{MCH}$ care and parallel terms for challenges, opportunities and successes (Additional file 2). The selected key words were searched in following databases; PubMed, Embase, Scopus, CINAHL, PsycINFO, WHO research portal, and Google scholar. The PROSPERO registry was also searched for the confirmation of none existence of ongoing or recently completed similar systematic reviews.

\section{Selection process}

Original studies conducted in SEAR countries on any component of UHC in relation to MCH and which identified challenges, opportunities and successes towards UHC were included in the review. Systematic reviews, scoping reviews and document reviews were excluded. Only studies published in English language and published before 2010 were included. The search was restricted to after 2010 as there has been more improvement in research on UHC with the shifting from millennium development goals to Sustainable development goals 2015. Inclusion and exclusion criteria are clearly described in table 1.

\section{Table 1: Inclusion and exclusion criteria}

\begin{tabular}{|c|c|c|}
\hline & Inclusion criteria & Exclusion criteria \\
\hline \multirow[t]{2}{*}{$\begin{array}{l}\text { Study } \\
\text { design }\end{array}$} & $\begin{array}{l}\text { Regardless of methodology all original research } \\
\text { papers on Universal health coverage in relation to } \\
\text { maternal and child health done in SEAR countries, } \\
\text { which identified challenges or opportunities or } \\
\text { successes were included. }\end{array}$ & $\begin{array}{l}\text { Letters, editorials, reviews, } \\
\text { narrative reviews and systematic } \\
\text { reviews were excluded. Studies } \\
\text { conducted in countries not in } \\
\text { SEAR were excluded }\end{array}$ \\
\hline & & $\begin{array}{l}\text { Studies which not identified } \\
\text { challenges or opportunities or } \\
\text { successes were excluded }\end{array}$ \\
\hline Language & Studies published in English were included & $\begin{array}{l}\text { Studies published in languages } \\
\text { other than English were excluded }\end{array}$ \\
\hline $\begin{array}{l}\text { Publication } \\
\text { date }\end{array}$ & $\begin{array}{l}\text { Only studies published after } 1^{\text {st }} \text { of January } 2010 \text { were } \\
\text { included. }\end{array}$ & $\begin{array}{l}\text { Studies published before } 2010 \\
\text { were excluded }\end{array}$ \\
\hline
\end{tabular}

Initial search was conducted on $3^{\text {rd }}$ of February 2020. All identified papers were imported into EndNote referencing software. After removal of the duplications, the titles and abstracts were screened for relevance and eligibility criteria. Then the remaining full text papers were read and re-evaluated for data extraction. Inappropriate papers were excluded from the study. The identified successes/ opportunities and challenges were extracted separately in accordance with access, coverage, equity and quality of the services. The 
extracted data were presented as a narrative synthesis according to WHO six building blocks of health systems. Findings of the review were organized and presented in accordance with objectives of the study.

\section{Risk of bias (quality) assessment}

Quality appraisal of the selected full text studies was concomitantly carried out. All included articles were assessed for reporting quality by using appropriate checklists according to the study design. Assessment tools designed by Joanna Briggs Institute (JBI) were used ${ }^{11}$. The JBI qualitative checklist included 10 questions and each question included four options "Yes," "No," "unsure" or "not applicable". Likewise, the JBI checklist for quantitative studies and intervention studies has 8 and 9 items respectively. Marks were given accordingly as, yes $=1$, no $=0$ and unsure $=0$. At the end of the evaluation of each of the included studies, we gave a score above $80 \%$ as high quality, $60-80 \%$ as medium quality and below $60 \%$ as low quality. In mixed method studies, two parts were assessed separately with both qualitative and quantitative checklists. A field trial was assessed with non-randomized control trial checklist (Additional file 3). No studies were excluded as a result of the quality assessment. However, the methodological rigor of each study added the confidence assessments of each review finding.

\section{Results}

The literature search initially identified 3747 papers published between January 2010 and January 2020. One thousand one hundred and eighty nine of these papers were found to be duplicates while 1192 papers were excluded by reading their titles only. One thousand two hundred and fifty four papers were excluded by reading their abstracts, as they were not related to the objectives of the study. Another 19 articles were excluded, as they were only abstract or poster presentations in conferences. Then the full texts were reviewed with 92 papers, which excluded 30, as they have not identified challenges and opportunities (Figure 1-PRISMA flow chart).

Among studies included in the review, a majority was from India $(n=30,48 \%)^{(12-41)}$. There were 11 studies from Nepal ${ }^{(42-52)}, 10$ from Bangladesh ${ }^{(53-62)}$, six from Indonesia ${ }^{(63-68)}$ and two from Timor-Leste ${ }^{69,70}$. From Bhutan $^{71}$, Thailand ${ }^{72}$, and Myanmar ${ }^{73}$ one from each was identified. Unfortunately, no study could be included from Sri Lanka, Maldives and Democratic Republic of Korea. When considering the publication year of the article, majority of selected articles were published in $2018(n=16,26 \%)$. In total, 21 quantitative, 33 qualitative, 07 mixed-methods and one field trial were found. Nine quantitative studies, 20 qualitative studies and five mix method studies found to be of high quality studies. The rest were found to be medium quality studies. A data table constructed for selected studies including important characteristics such as author, year of publication, country, study design, sample size, study objectives and quality assessment is attached as Additional file 4.

We found 62 articles related to the successes, challenges and opportunities for $\mathrm{UHC}$ with relation to $\mathrm{MCH}$ in WHO SEAR countries. We were able to categorize our findings in relation to access, coverage, equity and quality of maternal and childcare services. Summarized tables of extracted data are presented on Additional file 5. A narrative description of the successes and opportunities and the challenges are presented in the next section. 


\section{Successes and opportunities for UHC to MCH according to health system building blocks}

\section{a. Service delivery}

Successes and opportunities in access to $\mathrm{MCH}$ services were identified in the region. In Bhutan, antenatal clinics conducted in primary healthcare level are an important means of reaching the ANC services to women in rural areas with difficult geographical accessibility ${ }^{71}$. In a study conducted among Scheduled-Caste (SC) women in Bihar, India, revealed that the changes in the cultural acceptability of institutional delivery are facilitating the use of maternal health services by them ${ }^{27}$. Another study revealed that rural south Indian communities regularly use health care services during pregnancy and for delivery. New government programmes that increase availability of maternity services are supportive factors for the usage ${ }^{39}$. A study conducted among Nepal women has identified family support, transport availability and nearby birthing center as facilitators for institutional deliveries ${ }^{52}$. In Indonesia, a research revealed that all private and public hospitals in a province provide full coverage of Comprehensive Emergency Obstetric and New-born Care ${ }^{64}$. Support from friends, family and co-workers and male participation in accessing antenatal clinics are identified as enablers for early ANC booking in Bhutan ${ }^{71}$.

As a success in equity, National Rural Health Mission, a community intervention in India, had Improved $\mathrm{MCH}$ outcomes for the poor in rural areas with reduction of geographical and socioeconomic inequalities ${ }^{17}$. There detected a marked reduction of inequity among rural and urban antenatal care in Bangladesh between 2001 and $2010^{58}$.

Few opportunities have been identified in quality of $\mathrm{MCH}$ care service delivery in India. One study detected that there are quality enablers in health care institutions such as appreciation of public-private partnerships, availability of clinical guidelines in the form of wall posters in health facilities, efforts to translate knowledge and evidence through practice and enthusiasm towards value of guidelines ${ }^{22}$. Another study has spotted that improved skills and confidence among providers, inclusion of doctors in training, increased training frequency, administrative support, and nursing supervision and feedback as factors for facilitating obstetric and neonatal emergency care $^{26}$. In Bangladesh, for the management of SAM in children, there are proper guidelines, cadres and inpatient management facilities as identified by a study carried out to assess preparedness ${ }^{55}$.

\section{b. Healthcare Financing}

To achieve $\mathrm{UHC}$ in $\mathrm{MCH}$, under the national health mission of India, several cash schemes such as Janani Suraksha Yojana Janani Shishu Suraksha Karyakram and Chiranjeevanie Yojana have been introduced. These programmes provide improvements in maternal health care in India 14,18, 27,34,37,40. They further provide contracting in EmOC specialists in private sector as a measure to reduce maternal mortality ${ }^{29}$. In Nepal, Bangladesh and Indonesia, there are similar programmes to facilitate maternal care including institutional delivery $42,43,52,57,59,63,64,66,67$. For the improvement of access to needy mothers and children, government of India has provided accreditation of private sector health providers in government-led schemes for maternity services. Under those schemes, the private sector can potentially play an important complementary role to the public sector for maternity services $34,40,41$. As a positive factor that both government representatives and private practitioners have expressed enthusiasm in collaborating with each other with those programmes ${ }^{41}$ 


\section{c. Human resources}

A success / opportunity with availability of adequate human resources for delivery care across most public health facilities has been identified only in one study in India ${ }^{30}$. Accredited Social Health Activists (ASHAs) play a key role in facilitating the adoption of safe practices in postnatal care in India ${ }^{36}$. Another study identified having 24 hour availability of midwives and friendly service providers in rural areas of Nepal ${ }^{52}$. Service providers are identified as motivated to deliver quality post-partum family planning services and transfer their knowledge to colleagues that lead to provision of high quality post-partum family planning services in Nepal ${ }^{51}$.Immunization staff and other health staff are aware of the evidence-based planning approach in immunization in Bangladesh ${ }^{54}$.

\section{d. Health information management system (HIMS)}

As a success with HIMS, records for $\mathrm{MCH}$ services at a state in India were detected as satisfactory ${ }^{31}$.

\section{e. Leadership and governance}

Jat et. al. has noted that maternal health has become a political priority in India. There is a supportive policy environment with greater political will and better resources. This leads to several opportunities in terms of policies, guidelines and programmes for improving maternal health ${ }^{19}$. Regarding maternal nutrition, India has a better collection of programs and policies which can play a major role in improving $\mathrm{MCH}$ outcomes ${ }^{28}$. According to Maloney et al, supportive leadership and staff motivation facilitates the implementation of standards aimed at reducing common causes of maternal death in government hospitals in India ${ }^{25}$.

\section{Challenges for UHC to MCH according to health system building blocks}

\section{a. Service delivery}

Several common challenges were identified in the region in relation to access in $\mathrm{MCH}$ care services, which included clients' factors as well as providers'. Lack of knowledge on local health system, misconceptions and mistrust about public health system and lack of time for attending clinics were among clients' factors within vulnerable populations in India ${ }^{33}$. Feelings of shame and embarrassment, fear of repercussion for discussing their pregnancies with their doctors, and inadequate time with their doctors were identified as barriers for access in India ${ }^{15}$. Underestimation of the severity of the condition, especially in post-partum by family was a main challenge for looking timely postpartum care ${ }^{20}$. In a study conducted in India, it revealed that receiving postpartum care is rare for maternal problems. The main reason was the lack of recognition that a large proportion of maternal morbidity and mortality occurs in the postpartum period ${ }^{39}$. Another study revealed that cultural barriers include cultural norms such as preference over male infant and traditional clinical practices delays maternal care seeking among Indian women ${ }^{38}$.

In addition to that, lack of access to health care related information was detected as a challenge for decision to seek proper care in $\mathrm{MCH}^{15}$. The preference of pregnant women to deliver in their parents' village and the use of traditional birth attendants were some obstacles in access in Indonesia ${ }^{63}$. Delayed first antenatal visit was common in Bhutan due to lack of gender insensitivity in providing care through male health workers and cost 
and time in clinic visits ${ }^{71}$. Several harmful cultural practices and beliefs are identified as barriers for institutional delivery in $\mathrm{Nepal}^{42,45,46,49,52}$. Perceived low-quality services are barriers for delivery and postpartum care access for rural Indian and Nepal women 20,39,44,45. Financial constrains due to poverty was detected as an overarching structural barrier for access $38,39,46$.

Male controlled family structures, intergenerational decision-making and cultural attitudes towards reproductive health information and service has reduced women's access to reproductive health services in Timor-Leste ${ }^{69}$. Distance to health facilities, difficulty in geographical access, high transport costs, poor roads and lack of transportation facilities were identified as challenges for access to $\mathrm{MCH}$ care institutions

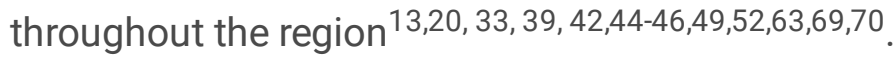

Several studies reported that the low quality of delivery and postpartum care provided by the institutions is a major challenge for health care access in the region $44,49,69,70$. The low quality is reflected with poor infrastructure, unfriendly health care providers, hospital policies and poor staff attitude. The restricted hours of opening, the lack of availability of medical resources and the lack of privacy are identified in maternity services in Timor-Leste ${ }^{69}$.

Regarding the service coverage, study done in child immunization revealed the challenges for low coverage of immunization in Bangladesh included lack of quantity and quality of supervision, lack of basic immunization supplies and some technical issues such as issues on doses, registration, and poor communication with communities ${ }^{54}$. With regard to equity on access of maternal services, inequity was detected in service delivery to migrant women working in brick kilns ${ }^{33}$ and SC women in India ${ }^{27}$. There are considerable socio-economic and geographic inequities in newborn care in Indonesia ${ }^{65}$. In Nepal, inequity persists in care seeking for childhood diarrhea and respiratory symptoms among poor, less educated mothers over 15 years 48 .

When considering the quality of $\mathrm{MCH}$ care, facility readiness was detected as poor for emergency obstetric care and newborn care in public and private health facilities including primary care facilities both rural and urban areas in India, Nepal and Bangladesh21,31,47,56. Several studies detected inadequate infrastructure leads to poor quality in maternal and child care including family planning services in the region ${ }^{12,22-}$

$24,26,28,38,45,51,52,56,60,65,73$. In addition to those problems, irregular supply of water and electricity, lessfunctioning of blood bank ${ }^{12}$, inadequate laboratory facilities ${ }^{12,56,61}$ were detected as challenges. Difficulty in maintaining privacy is another structural barrier ${ }^{12}$. Overcrowded health facilities and lack of health facility accreditation were detected as challenges for quality in maternal healthcare in Indonesia ${ }^{63}$. High volume of patients leads to suboptimal quality care in emergency obstetric care in rural Bangladesh ${ }^{56}$. The rural birthing centers in Nepal are not providing quality services due to unavailability of 24-hour services as identified by Khatri ${ }^{45}$.

In two rural districts of Uttar Pradesh, India, process gaps are observed during delivery and post-delivery stages compromising mothers' safety and quality care ${ }^{30}$. Few other studies pointed out the problems with referral system for the contribution of poor quality $12,36,38,65$. According to Puett et al, referrals by community health worker of childhood conditions are treated with low quality in Southern Bangladesh institutions ${ }^{60}$. It acts as a challenge for community management of them. Health service responses for postpartum care are identified as 
poor and non-patient-centered in a study done in Indonesia ${ }^{64}$. Postnatal care at village level is identified as non-patient-centered care practices in Klaten district, central Java Province, Indonesia ${ }^{68}$.

Few other challenges were identified in quality service delivery with regard to providers'. Unwillingness of provider to apply new techniques also acts as barriers for quality care ${ }^{65}$. In Myanmar, poor quality of maternal and perinatal health care detected due to inadequate relationships between health cadres ${ }^{73}$. Interpersonal behavior among staff as well as patient's relatives which leads to less information sharing is another barrier for quality care ${ }^{12}$. Hierarchy in healthcare workers is a challenge to care provision of obstetric and neonatal emergency care in primary care facilities in Bihar, India ${ }^{26}$. Inadequate or lack of training of health staff is another problem in quality services $23,56,73$. Antenatal care is typically delivered at the periphery by nonspecialized providers in rural Karnataka State ${ }^{39}$. Following providers' behaviors were identified as challenges for quality maternal and childcare in few institutions; Negligence by health staff ${ }^{20}$, rudeness of staff against clients ${ }^{25}$, abuse and demand for informal payments ${ }^{30}$. Cultural norms and practices also play a role in quality care as identified by few studies in the region $26,36,73$. Few studies have identified that high out of pocket expenditure is a challenge for quality maternal and child care ${ }^{12,62}$.

\section{b. Healthcare financing}

Even though there are government funded health beneficiary programmes in India, challenges for the proper implementation exist. The health facilities are in poor quality and provide suboptimal benefits due to lack of resources and various interactions, which lead to poor utilization of facilities ${ }^{18}$. Identified challenges for low participation of private practitioners in government-funded programmes are low and delayed reimbursements, poor infrastructure and administrative issues ${ }^{29,41}$. Despite the government's efforts at increasing access to delivery services for poor women in the private sector with programmes, uptake was low ${ }^{34}$. Partial health insurance cover for migrant women working in brick kilns in district Faridabad, Haryana, India, is an access barrier for them to maternal health utilization ${ }^{33}$. Lack of proper documentation for health insurance registration is a perceived barrier for Jamkesmas health insurance membership in Indonesia ${ }^{63}$. High out of pocket expenditure is a major barrier to access to appropriate medicine in children in rural Bangladesh ${ }^{62}$.

Challenge in equity was detected with low receipt of JSY benefits among mothers in Odisha and Jharkhand area, India ${ }^{37}$. Receipt of the benefits is highly variable, not equally distributed, favoring wealthier groups. The JSY scheme is currently not sufficient to close the poor-rich gap in institutional delivery rate ${ }^{37}$. Shortage of human resources was a major health system barrier for implementation of National Rural Health Mission which implemented in India from 2005 to 2012 to reduce $\mathrm{MCH}$ inequalities ${ }^{17}$.

\section{c. Human resources}

Inadequate healthcare workers including specialists was identified as a challenge for provision of better maternal and neonatal care in India, Nepal, Bangladesh, Indonesia, Timor-Leste and Myanmar $12,22,24,26,29,8,45,47,49,51,56,61,63,69,73$. Shortage of staff is widespread in rural areas. Provider incompetence in emergency obstetric care and neonatal care are another problem detected by many researchers over the region ${ }^{21,52}$. Lack of skills for post-delivery counseling is a challenge for provision of quality maternity care ${ }^{12}$. 
Suboptimal knowledge and skills among workers in the field leads to poor quality $\mathrm{MCH}^{22,35,47,65,68}$. Few social, professional and economic barriers are identified with midwifery personnel in Bangladesh which preventing quality maternity care ${ }^{53}$. Staff nurses involving maternal, newborn, and child healthcare in government public health facilities in Uttar Pradesh, India, are working in stressful environment which may lead to low quality of services ${ }^{16}$.

\section{d. Medical products}

Several studies detected that lack of adequate supplies and drugs affects the quality in maternal and child care including family planning services in the region $12,22,38,51,56,60$. Unavailability of medicines and therapeutic diet in facilities was detected as a challenge for management of SAM in Bangladesh ${ }^{55}$.

\section{e. Governance and leadership}

Poor governance in birthing centers ${ }^{45}$, lack of support from hospital administration ${ }^{51}$ and less priority given on primary health care ${ }^{50}$ are the barriers identified in Nepal for good quality delivery and postpartum care. In Indonesia, decentralization of the health sector which created confusion regarding roles and responsibilities as well as complex administration process were identified as important factors which impede the quality care 64 , 65. Vogel et al has identified that the deficiencies in policies and political context and deficiencies with accountability and monitoring as the barriers to implement WHO Maternal and perinatal health recommendations in Myanmar ${ }^{73}$. Health policy on maternal care are not focusing on adolescent pregnancy in Thailand. It is recognized as a challenge in provision of quality care for pregnant adolescent women ${ }^{72}$. Pertaining to management of SAM in children in Bangladesh, there detected a conflict situation among nutrition stakeholders and problems in nutrition coordination 55.

\section{Risk of bias assessment}

The quality appraisal checklists developed by JBI cover the appropriateness of the research design and standard conceptions for assessing risk of bias and overall quality. The quality assessment helped to collect the strengths and weakness of the evidence summarized by the whole review. All quantitative studies included here are medium in quality due only to failure to identify and mention how they dealing with confounding factors. Twenty one out of 33 qualitative studies are medium due to lack of a statement on locating and influence of the researcher. However, research objectives, data collection and analysis and ethical aspects are presented nicely. Only one qualitative study failed to mention specifically in ethical approval even though other ethical aspects were mentioned ${ }^{27}$. Nine quantitative studies out of $21(43 \%), 20$ qualitative studies out of 33 $(61 \%)$ and five mix method studies out of seven (71\%) found to be of high quality studies. Altogether 34 (55\%) studies had high quality. The rest of them were found to be medium quality studies. No study was excluded nor weighted due to quality assessment, but the quality is used to inform data interpretation.

\section{Discussion}

In this study we explored the successes and opportunities and the challenges encountered by SEAR countries towards $\mathrm{UHC}$ in $\mathrm{MCH}$ care. Results are presented according to WHO six building blocks; service delivery, health 
care financing, human resources, healthcare information, medical products and leadership, and governance, with regard to access, coverage, equity and quality of $\mathrm{MCH}$ care.

We have detected opportunities to increase access to $\mathrm{MCH}$ services throughout the SEAR: public and private partnership, availability of facilities, cultural changes and family support. Government led cash transfer programmes improve $\mathrm{MCH}$. Inequity has reduced in $\mathrm{MCH}$ services. Quality of the $\mathrm{MCH}$ has improved with motivated human resources and with political priority.

There are also a number of common challenges, which are preventing countries to achieving $\mathrm{UHC}$ in $\mathrm{MCH}$ services. Low health literacy, less ability to recognize post-partum issues, misconceptions and cultural barriers prevents mothers and children in SEAR from appropriate healthcare access. Difficult geography and transport problems, including high transport cost, worsens the condition. Poverty is an overarching challenge throughout the region leading to health inequity. Poor infrastructure facilities and some administrative issues reduce the benefits from government led cash transfer programmes. Inequity in $\mathrm{MCH}$ care persists for vulnerable populations in the region even in state beneficiary programmes.

Healthcare facilities which are providing low quality services with fewer resources are the other major challenge. Poor infrastructure including buildings, laboratory and blood bank facilities, medical products and other supplies with high volume of patients vastly contribute to reduced quality. Unavailability of 24-hour services and inability to maintain privacy are the problems related to public facilities. Inadequate HCW has a major contribution to poor quality. Healthcare personnel's inappropriate behaviors like negligence, abuse, corruption, poor relationships and unwillingness for change are attributing to poor quality. Poor knowledge and skills due to inadequate training and workplace stress of HCW has a contribution to poor quality. Lack of supervision is another challenge in quality. Deficiencies in government policies and administration were identified in some fields which hindering the quality services in $\mathrm{MCH}$.

In order to address these challenges, regional countries have implemented several initiatives. Numerous cash transfer schemes in SEAR countries facilitate the maternal and childcare including institutional deliveries as detected in our review. It is tally with Hunter et al in their consolidated systematic review ${ }^{74}$. Contracting nongovernment health providers is an important step in reducing maternal mortality in India. The finding is in line with data obtained from LMIC by Rao et al. ${ }^{75}$.

Our review identified client perspectives such as lack of awareness and education as well as various cultural barriers as challenges for access to $\mathrm{MCH}$ care. These findings are consistent with results from reviews done in African countries ${ }^{76-78}$, and $\mathrm{LMIC}^{79}$. This review also highlights the difficult geography and transport problems as a main barrier for access which comparable with number of reviews from LMIC including Africa 76,77,80,81.

We identified that the shortage of human resources was a major barrier for better quality $\mathrm{MCH}$ care. Our result is in line with findings from LMIC $^{81}$, Sub-Saharan Africa ${ }^{76}$ and a global situation analysis ${ }^{82}$. Even in developed countries, lack of trained staff is a key challenge in maternal care in underserved areas ${ }^{83}$. A systematic review published in 2019 on the effect of UHC on equitable access to care in African countries shows that shortages in human resources act as a main barrier in access to health services ${ }^{77}$. Human resources are critical to the expansion of health service coverage as described by Campbell et al. ${ }^{84}$. HCWs' 
inappropriate behaviors such as rudeness, abuse, negligence, poor coordination etc. act as a challenge for quality as shown here. The findings are compatible with other reviews on $\mathrm{MCH}$ quality care throughout the world $76,81,85$. This review finds that infrastructure in healthcare facilities including buildings and different medical supplies affect the quality of care. This agrees with findings from few other studies in sub-Saharan Africa countries ${ }^{76,86}$ as well as from LMIC $^{81}$ and a global situation analysis ${ }^{82}$.

The current review has the following strengths. To our knowledge, this is the first systematic review done on $\mathrm{UHC}$ in relation to $\mathrm{MCH}$ care in SEAR. The review accessed several databases and used recent publications less than 10 years old. It involved a large number of studies that covered different geographical areas in many SEAR countries. Methodologically, we included articles conducted with quantitative, qualitative, and mixedmethods study designs. Therefore, broader findings were represented rather than a homogeneous source. The studies included in this review have given remarkable findings on the present topic. More than half $(55 \%, n=34)$ of the studies were assessed as high quality while no poor quality studies. Quality of included articles was appraised using a standard quality appraisal tools developed by accredited institute and used in systematic reviews widely. Even though nearly half of the included studies were conducted in India, the generalizability will not affect once considering the population distribution. We strictly adhered to the inclusion and exclusion criteria in selection process, which improved the quality of our findings.

This review has some limitations. We could include only articles published in English and indexed in PubMed, CINAHL, Embase, Psych Info, and Scopus. Gray literature, including government reports, was not included in the review. Therefore a possibility that some relevant studies published in other language or indexed elsewhere been missed cannot be excluded. We were unable to include even a single papers from three countries in SEAR, as there were none detected in our search strategy. Further, we could not perform meta-analysis of the findings due to the heterogeneity of the outcome measures and methods employed.

\section{Implications of the review findings}

Overall, despite the above limitations, the study findings have important implications reaching UHC in $\mathrm{MCH}$ in the SEAR. As the shortage of HCWs is critical towards UHC, training and recruiting more staff is a priority in the region. However, a mere increase in the number will not improve the quality and accessibility of services as poor attitude and lack of skills have a major contribution. Therefore, persistent competencies, skills, and attitude development programs should be continuing throughout the service ages of HCW. For the countries in the region that have sufficient private sector health staff, contracting them in public maternal and child care will have a benefit to ultimately reaching UHC. However, these programmes should be supervised thoroughly.

Government led insurance schemes report increased utilization of $\mathrm{MCH}$ care in countries, even though there may be other interrelated factors which responsible for the improvement. Healthcare financing requires sustained investments on capital and recurrent budget for infrastructure facilities as well as government led insurance programmes. Cash transfer programmes involve handling of large amount of money. Hence administrators must be vigilant to minimize corruption in these programmes. It is recommended to regularly review health expenditure by the governments in $\mathrm{MCH}$ care and related spending to commitments. Investments on healthcare infrastructure including buildings, medical products and other equipment as well as capacity building programmes in staff and communities will lead to improve access, quality, equity and coverage in 
long run. Health insurance facilities should be made available for $\mathrm{MCH}$ care whenever possible as the poverty is an overarching barrier there. Special focus should be given in policy making on the under-privileged communities as they are more vulnerable to not getting due $\mathrm{MCH}$ care which eventually obstructing UHC.

The review has identified a large number of challenges, which impede health of mothers and children in the region. Effective implementation of strategies after controlling these challenges would lead to significant improvement in $\mathrm{MCH}$ care. We identified cultural and societal practices, which prevent provision of proper care to mothers and children. Therefore, it is recommended to incorporate culturally sound modifications in health system reforms wherever possible. Women should be empowered to take decisions of their healthcare as the other family members may support her. The findings suggest that the post-natal care has affected more than antenatal and natal care. The current and future efforts towards UHC in the region should be focused on postnatal care.

Solutions for some of the identified challenges are beyond the health system capacity, which need multisectorial approach. Low health literacy should be addressed even through early ages of life with education system. Due to the fact that more than quarter of the world population inhabit in the region, the high volume of patients are inevitable. Poverty elimination will be the most difficult goal to be achieved. As it persists due to geography of the country, difficult terrain issues are hard to solve with limited resources. They should be solved with long term strategies with the help of other authorities outside health. Transport problems including poor road structure, lack of vehicles and high cost of transport should be dealing with many other organizations in the government and non-governmental sectors. All the above mentioned non health solutions as well as health sector solutions are bound tightly with political decisions. Therefore, politics in the region should be supported with WHO and other global organizations.

Policy-makers and policy implementers should work together to strengthen the health system, and mitigate challenges. Inter-sectoral collaboration should be strengthened, and all stakeholders should cooperate and work together to overcome challenges that are observed at multiple levels. Political commitment by national as well as regional leaders is needed to build sustainable programmes that eventually lead to achievements of $\mathrm{UHC}$ in $\mathrm{MCH}$ care. Although the implications here are for whole SEAR countries, country specific interventions which are able to tackle specific challenges will be needed.

\section{Implications to future research}

This review found that there is limited availability of quantitative evidence regarding UHC. Further no research could be found in three countries in the region. It is important to encourage SEAR countries to build capacity for research on UHC. Future researches on the exploration of new opportunities and challenges will be helpful to improve MCH not only in the SEAR, but the globally.

\section{Conclusions}

Countries in SEAR have achievements in UHC with improvements of access, quality and equity on $\mathrm{MCH}$. However, all have further way to go with the challenges on human and other resources, health care facilities and non-health related issues. Health care worker recruitments with continuous trainings and investments on health care programmes with due priority are a need of the time. Proper attention should be given to under 
privileged groups to minimize inequity. Regional bodies as well as authorities in individual countries should work together to address common major challenges. Ministries of Health in relevant countries, in collaboration with other stakeholders should take immediate actions to strengthen the access and quality of $\mathrm{MCH}$ in order to achieve UHC.

\section{List Of Abbreviation}

ANC : Antenatal care

ASHA : Accredited Social Health Activists

CJY : Chiranjeevanie Yojana

HCW : Health care worker

HIMS : Health information management system

$\mathrm{JBI}$ : Joanna Briggs Institute

JSY : Janani Suraksha Yojana

LMIC : Low - and middle -income countries

$\mathrm{MCH}$ : Maternal and child health

NRHM : National Rural Health Mission

PRISMA : Preferred reporting items for Systematic reviews and Meta-Analyses

PROSPERO : Prospective Register of Systematic Reviews

$\mathrm{RH}$ : Reproductive health

SAM : Severe acute malnutrition

SC : Scheduled- caste

SDG-3 : Third Sustainable Development Goal

SDG : Sustainable Development Goal

SEAR : South East Asian Region

UHC : Universal health coverage

$\mathrm{UHCl}$ : UHC services coverage index

WHO : World Health Organization 


\section{Declarations}

Ethics approval and consent to participate : Not applicable

Consent for publication : Not applicable

Availability of data and materials: Data sharing is not applicable

Competing interests : None

Funding : No funding was received for this work.

Authors' contributions : UAPP and YA designed the study, selected articles, appraised the articles, and synthesized the data. UAPP wrote the first draft of the manuscript. UAPP, CG and YA interpreted the data and contributed the final writing of the manuscript. All authors read and approved the final manuscript.

Acknowledgements : Staff of School of Public Health, the University of Queensland

Authors' information : UAPP is a visiting research fellow attached to the School of Public Health: YA is a senior lecturer in Global Health in the School of Public Health and CG is the Head of the school, the School of Public Health, The university of Queensland.

\section{References}

1. United Nation Development Programme (2020) Sustainable Development Goals https://www.undp.org/content/undp/en/home/sustainable-development-goals.html (Accessed on $10^{\text {th }}$ February 2020)

2. World Health Organization. Regional Office for South-East Asia. (2019). https://apps.who.int/iris/handle/10665/329426(Accessed on $11^{\text {th }}$ March 2020)

3. World Health Organization (2020-1)

I UniversalHealth Coverage https://www.who.int/healthsystems/universal_health_coverage/en/ (Accessed on $11^{\text {th }}$ March 2020)

4. 4. World Health Organization (2020-2) Universal health coverage- Fact sheet https://www.who.int/newsroom/fact-sheets/detail/universal-health-coverage-(uhc) (Accessed on $11^{\text {th }}$ March 2020)

5. World Health Organization (2020-

3) https://www.who.int/health_financing/universal_coverage_definition/en/ (Accessed on $11^{\text {th }}$ March 2020)

6. World Health Organization (WHO). Universal health coverage. 2017. http://www.who.int/universal_health_coverage/en/ (accessed 27 May 2020).

7. World Health Organization (WHO).Monitoring Report 2019 https://www.who.int/healthinfo/universal_health_coverage/report/2019/en (Accessed 5th June 2020) 
8. World Health Organization (2020-4) About WHO in the SEARO https://www.who.int/southeastasia/about (accessed 19th March 2020)_(Accessed on 20

9. World Health Organization (2020-5) https://www.who.int/southeastasia/news/speeches/detail/universalhealth-coverage-day-2019 (Accessed $10^{\text {th }}$ March 2020)

10. Liberati A, Altman DG, Tetzlaff J, Mulrow C, Gøtzsche PC, loannidis JPA, et al. The PRISMA statement for reporting systematic reviews and meta-analyses of studies that evaluate healthcare interventions: explanation and elaboration. BMJ. 2009; 339:b2700

11. The Joanna Briggs Institute (Available from http://joannabriggs-webdev.org/research/critical-appraisaltools.html) accessed on 15 March 2020

12. Bhattacharyya S, Issac A, Rajbangshi P, Srivastava A, Avan BI. "Neither we are satisfied nor they"-users and provider's perspective: a qualitative study of maternity care in secondary level public health facilities, Uttar Pradesh, India. BMC health services research. 2015;15:421.

13. Bruce SG, Blanchard AK, Gurav K, Roy A, Jayanna K, Mohan HL, et al. Preferences for infant delivery site among pregnant women and new mothers in Northern Karnataka, India. BMC pregnancy and childbirth. 2015;15:49.

14. Chaturvedi S, De Costa A, Raven J. Does the Janani Suraksha Yojana cash transfer programme to promote facility births in India ensure skilled birth attendance? A qualitative study of intrapartum care in Madhya Pradesh. Global health action. 2015;8:27427.

15. Das A, Sarkar M. Pregnancy-related health information-seeking behaviors among rural pregnant women in India: validating the Wilson model in the Indian context. The Yale journal of biology and medicine. 2014;87(3):251-62.

16. Engl E, Kretschmer S, Jain M, Sharma S, Prasad R, Ramesh BM, et al. Categorizing and assessing comprehensive drivers of provider behavior for optimizing quality of health care. PloS one. 2019;14(4):e0214922.

17. Gupta M, Bosma H, Angeli F, Kaur M, Chakrapani V, Rana M, et al. Impact of a Multi-Strategy Community Intervention to Reduce Maternal and Child Health Inequalities in India: A Qualitative Study in Haryana. PloS one. 2017;12(1):e0170175.

18. Gupta A, Fledderjohann J, Reddy H, Raman VR, Stuckler D, Vellakkal S. Barriers and prospects of India's conditional cash transfer program to promote institutional delivery care: a qualitative analysis of the supply-side perspectives. BMC health services research. 2018;18(1):40.

19. Jat TR, Deo PR, Goicolea I, Hurtig AK, San Sebastian M. The emergence of maternal health as a political priority in Madhya Pradesh, India: a qualitative study. BMC pregnancy and childbirth. 2013;13:181.

20. Jat TR, Deo PR, Goicolea I, Hurtig AK, San Sebastian M. Socio-cultural and service delivery dimensions of maternal mortality in rural central India: a qualitative exploration using a human rights lens. Global health action. 2015;8:24976.

21. Jayanna K, Mony P, B MR, Thomas A, Gaikwad A, H LM, et al. Assessment of facility readiness and provider preparedness for dealing with postpartum haemorrhage and pre-eclampsia/eclampsia in public and private health facilities of northern Karnataka, India: a cross-sectional study. BMC pregnancy and childbirth. 2014;14:304. 
22. Karvande S, Sonawane D, Chavan S, Mistry N. What does quality of care mean for maternal health providers from two vulnerable states of India? Case study of Bihar and Jharkhand. Journal of health, population, and nutrition. 2016;35:6.

23. Karvande S, Sonawane D, Samal J, Mistry N. Family planning training needs of auxiliary nurse midwives in Jharkhand, India: Lessons from an assessment. The National medical journal of India. 2018;31(2):73-8.

24. Kaur J, Franzen SRP, Newton-Lewis T, Murphy G. Readiness of public health facilities to provide quality maternal and newborn care across the state of Bihar, India: A cross-sectional study of district hospitals and primary health centres. BMJ Open. 2019;9(7).

25. Maloney SI, Siahpush M, Dinkel D, Farazi PA, Jose J, Dutta R. Nurse and physician reflections on the application of a quality standards training program to reduce maternal mortality. Midwifery. 2018;66:15560.

26. Morgan MC, Dyer J, Abril A, Christmas A, Mahapatra T, Das A, et al. Barriers and facilitators to the provision of optimal obstetric and neonatal emergency care and to the implementation of simulationenhanced mentorship in primary care facilities in Bihar, India: a qualitative study. BMC pregnancy and childbirth. 2018;18(1):420.

27. Patel P, Das M, Das U. The perceptions, health-seeking behaviours and access of Scheduled Caste women to maternal health services in Bihar, India. Reproductive health matters. 2018;26(54):114-25.

28. Ramakrishnan U, Lowe A, Vir S, Kumar S, Mohanraj R, Chaturvedi A, et al. Public health interventions, barriers, and opportunities for improving maternal nutrition in India. Food and nutrition bulletin. 2012;33(2 Suppl):S71-92.

29. Randive B, Chaturvedi S, Mistry N. Contracting in specialists for emergency obstetric care- does it work in rural India? BMC health services research. 2012;12:485.

30. Saxena M, Srivastava A, Dwivedi P, Bhattacharyya S. Is quality of care during childbirth consistent from admission to discharge? A qualitative study of delivery care in Uttar Pradesh, India. PloS one. 2018;13(9):e0204607.

31. Sharma A, Rana SK, Prinja S, Kumar R. Quality of Health Management Information System for Maternal \& Child Health Care in Haryana State, India. PloS one. 2016;11(2):e0148449.

32. Sharma J, Leslie HH, Regan M, Nambiar D, Kruk ME. Can India's primary care facilities deliver? A crosssectional assessment of the Indian public health system's capacity for basic delivery and newborn services. BMJ Open. 2018;8(6):e020532.

33. Siddaiah A, Kant S, Haldar P, Rai SK, Misra P. Maternal health care access among migrant women labourers in the selected brick kilns of district Faridabad, Haryana: mixed method study on equity and access. International journal for equity in health. 2018;17(1):171.

34. Sidney K, lyer V, Vora K, Mavalankar D, De Costa A. Statewide program to promote institutional delivery in Gujarat, India: Who participates and the degree of financial subsidy provided by the Chiranjeevi Yojana program. Journal of health, population, and nutrition. 2016;35:2.

35. Singh S, Doyle P, Campbell OMR, Murthy GVS. Management and referral for high-risk conditions and complications during the antenatal period: knowledge, practice and attitude survey of providers in rural public healthcare in two states of India. Reproductive health. 2019;16(1):100. 
36. Sinha LN, Kaur P, Gupta R, Dalpath S, Goyal V, Murhekar M. Newborn care practices and home-based postnatal newborn care programme - Mewat, Haryana, India, 2013. Western Pacific surveillance and response journal : WPSAR. 2014;5(3):22-9.

37. Thongkong N, van de Poel E, Roy SS, Rath S, Houweling TA. How equitable is the uptake of conditional cash transfers for maternity care in India? Evidence from the Janani Suraksha Yojana scheme in Odisha and Jharkhand. International journal for equity in health. 2017;16(1):48.

38. Vail B, Morgan MC, Dyer J, Christmas A, Cohen SR, Joshi M, et al. Logistical, cultural, and structural barriers to immediate neonatal care and neonatal resuscitation in Bihar, India 11 Medical and Health Sciences 1117 Public Health and Health Services. BMC pregnancy and childbirth. 2018;18(1).

39. Vidler M, Ramadurg U, Charanthimath U, Katageri G, Karadiguddi C, Sawchuck D, et al. Utilization of maternal health care services and their determinants in rural Karnataka State, India. International Journal of Gynecology and Obstetrics. 2015;131:E357.

40. Vora KS, Yasobant S, Patel A, Upadhyay A, Mavalankar DV. Has Chiranjeevi Yojana changed the geographic availability of free comprehensive emergency obstetric care services in Gujarat, India? Global health action. 2015;8:28977.

41. Yadav V, Kumar S, Balasubramaniam S, Srivastava A, Pallipamula S, Memon P, et al. Facilitators and barriers to participation of private sector health facilities in government-led schemes for maternity services in India: a qualitative study. BMJ Open. 2017;7(6):e017092.

42. Bhusal CL, Singh SP, Bc RK, Dhimal M, Jha BK, Acharya L, et al. Effectiveness and efficiency of Aama Surakshya Karyakram in terms of barriers in accessing maternal health services in Nepal. Journal of Nepal Health Research Council. 2011;9(2):129-37.

43. Ensor T, Bhatt H, Tiwari S. Incentivizing universal safe delivery in Nepal: 10 years of experience. Health policy and planning. 2017;32(8):1185-92.

44. Joshi D, Baral SC, Giri S, Kumar AMV. Universal institutional delivery among mothers in a remote mountain district of Nepal: What are the challenges? Public Health Action. 2016;6(4):267-72.

45. Khatri RB, Dangi TP, Gautam R, Shrestha KN, Homer CSE. Barriers to utilization of childbirth services of a rural birthing center in Nepal: A qualitative study. PloS one. 2017;12(5):e0177602.

46. Lama TP, Khatry SK, Katz J, LeClerq SC, Mullany LC. Illness recognition, decision-making, and care-seeking for maternal and newborn complications: a qualitative study in Sarlahi District, Nepal. Journal of health, population, and nutrition. 2017;36(Suppl 1):45.

47. Lama TP, Munos MK, Katz J, Khatry SK, LeClerq SC, Mullany LC. Assessment of facility and health worker readiness to provide quality antenatal, intrapartum and postpartum care in rural Southern Nepal. BMC health services research. 2020;20(1):16.

48. Malqvist M, Singh C, Kc A. Care seeking for children with fever/cough or diarrhoea in Nepal: equity trends over the last 15 years. Scand J Public Health. 2017;45(2):195-201.

49. Onta S, Choulagai B, Shrestha B, Subedi N, Bhandari GP, Krettek A. Perceptions of users and providers on barriers to utilizing skilled birth care in mid- and far-western Nepal: a qualitative study. Global health action. 2014;7:24580.

50. Paudel M, Javanparast S, Newman L, Dasvarma G. Health system barriers influencing perinatal survival in mountain villages of Nepal: implications for future policies and practices. Journal of health, population, 
and nutrition. 2018;37(1):16.

51. Puri MC, Maharjan M, Pearson E, Pradhan E, Dhungel Y, Khadka A, et al. Delivering postpartum family planning services in Nepal: are providers supportive? BMC health services research. 2018;18(1):948.

52. Shah R, Rehfuess EA, Paudel D, Maskey MK, Delius M. Barriers and facilitators to institutional delivery in rural areas of Chitwan district, Nepal: a qualitative study. Reproductive health. 2018;15(1):110.

53. Bogren M, Erlandsson K, Byrskog U. What prevents midwifery quality care in Bangladesh? A focus group enquiry with midwifery students. BMC health services research. 2018;18(1):639.

54. Grundy J, Rakhimdjanov S, Adhikari M. Policy opportunities and limitations of evidence-based planning for immunization: lessons learnt from a field trial in Bangladesh. WHO South-East Asia journal of public health. 2016;5(2):154-63.

55. Ireen S, Raihan MJ, Choudhury N, Islam MM, Hossain MI, Islam Z, et al. Challenges and opportunities of integration of community based Management of Acute Malnutrition into the government health system in Bangladesh: a qualitative study. BMC health services research. 2018;18(1):256-.

56. Islam F, Rahman A, Halim A, Eriksson C, Rahman F, Dalal K. Perceptions of health care providers and patients on quality of care in maternal and neonatal health in fourteen Bangladesh government healthcare facilities: A mixed-method study. BMC Health Services Research. 2015;15(1).

57. Islam MT, Igarashi I, Kawabuchi K. The impact of gonoshasthaya kendra's micro health insurance plan on antenatal care among poor women in rural bangladesh. BioScience Trends. 2012;6(4):165-75.

58. Kamal N, Curtis S, Hasan MS, Jamil K. Trends in equity in use of maternal health services in urban and rural Bangladesh. International journal for equity in health. 2016;15:27.

59. Mahmood SS, Amos M, Hoque S, Mia MN, Chowdhury AH, Hanifi SMA, et al. Does healthcare voucher provision improve utilisation in the continuum of maternal care for poor pregnant women? Experience from Bangladesh. Global health action. 2019;12(1):1701324.

60. Puett C, Alderman H, Sadler K, Coates J. 'Sometimes they fail to keep their faith in us': community health worker perceptions of structural barriers to quality of care and community utilisation of services in Bangladesh. Maternal \& child nutrition. 2015;11(4):1011-22.

61. Sikder SS, Labrique AB, Ali H, Hanif AA, Klemm RD, Mehra S, et al. Availability of emergency obstetric care (EmOC) among public and private health facilities in rural northwest Bangladesh. BMC Public Health. 2015;15(1).

62. Tahsina T, Ali NB, Hoque DME, Huda TM, Salam SS, Hasan MM, et al. Out-of-pocket expenditure for seeking health care for sick children younger than 5 years of age in Bangladesh: Findings from crosssectional surveys, 2009 and 2012. Journal of Health, Population and Nutrition. 2017;36(1).

63. Brooks MI, Thabrany H, Fox MP, Wirtz VJ, Feeley FG, Sabin LL. Health facility and skilled birth deliveries among poor women with Jamkesmas health insurance in Indonesia: a mixed-methods study. BMC health services research. 2017;17(1):105.

64. Diba F, Ichsan I, Muhsin M, Marthoenis M, Sofyan H, Andalas M, et al. Healthcare providers' perception of the referral system in maternal care facilities in Aceh, Indonesia: A cross-sectional study. BMJ Open. $2019 ; 9(12)$. 
65. Duysburgh E, Kerstens B, Diaz M, Fardhdiani V, Reyes KA, Phommachanh K, et al. Newborn care in Indonesia, Lao People's Democratic Republic and the Philippines: a comprehensive needs assessment. BMC pediatrics. 2014;14:46.

66. Kusuma D, Cohen J, McConnell M, Berman P. Can cash transfers improve determinants of maternal mortality? Evidence from the household and community programs in Indonesia. Social science \& medicine (1982). 2016;163:10-20.

67. Mukhlisa MN, Pujiyanto. The effect of health insurance on institutional delivery in Indonesia. Kesmas. 2018;12(3):148-52.

68. Probandari A, Arcita A, Kothijah K, Pamungkasari EP. Barriers to utilization of postnatal care at village level in Klaten district, central Java Province, Indonesia. BMC health services research. 2017;17(1):541.

69. King R, Jones L. Key factors deterring women's engagement with skilled birth attendants in three districts of Timor-Leste. A qualitative descriptive study. Midwifery. 2019;79.

70. Wallace HJ, McDonald S, Belton S, Miranda Al, da Costa E, Matos LDC, et al. The decision to seek care antenatally and during labour and birth - Who and what influences this in Timor-Leste? A qualitative project exploring the perceptions of Timorese women and men. Midwifery. 2018;65:35-42.

71. Dorji T, Das M, Van den Bergh R, Oo MM, Gyamtsho S, Tenzin K, et al. "If we miss this chance, it's futile later on" - late antenatal booking and its determinants in Bhutan: a mixed-methods study. BMC pregnancy and childbirth. 2019;19(1):158.

72. Jittitaworn W, Fox D, Catling C, Homer CSE. Recognising the challenges of providing care for Thai pregnant adolescents: Healthcare professionals' views. Women and Birth. 2019.

73. Vogel JP, Moore JE, Timmings C, Khan S, Khan DN, Defar A, et al. Barriers, Facilitators and Priorities for Implementation of WHO Maternal and Perinatal Health Guidelines in Four Lower-Income Countries: A GREAT Network Research Activity. PloS one. 2016;11(11):e0160020.

74. Hunter BM, Harrison S, Portela A, Bick D. The effects of cash transfers and vouchers on the use and quality of maternity care services: A systematic review. PLoS One. 2017;12(3):e0173068-e.

75. Rao KD, Paina L, Ingabire M-G, Shroff ZC. Contracting non-state providers for universal health coverage: learnings from Africa, Asia, and Eastern Europe. International Journal for Equity in Health. 2018;17(1):127.

76. Geleto A, Chojenta C, Musa A, Loxton D. Barriers to access and utilization of emergency obstetric care at health facilities in sub-Saharan Africa: a systematic review of literature. Syst Rev. 2018;7(1):183-.

77. Sanogo NdA, Fantaye AW, Yaya S. Universal Health Coverage and Facilitation of Equitable Access to Care in Africa. 2019;7(102).

78. Okedo-Alex IN, Akamike IC, Ezeanosike OB, Uneke CJ. Determinants of antenatal care utilisation in subSaharan Africa: a systematic review. BMJ Open. 2019;9(10):e031890-e.

79. Lassi ZS, Musavi NB, Maliqi B, Mansoor N, de Francisco A, Toure K, et al. Systematic review on human resources for health interventions to improve maternal health outcomes: evidence from low- and middleincome countries. Hum Resour Health [Internet]. 2016 2016/03//; 14:[10 p.]. Available from: http://europepmc.org/abstract/MED/26971317

80. Tegegne TK, Chojenta C, Loxton D, Smith R, Kibret KT. The impact of geographic access on institutional delivery care use in low and middle-income countries: Systematic review and meta-analysis. PLoS One. 
2018;13(8):e0203130.

81. Homer CSE, Castro Lopes S, Nove A, Michel-Schuldt M, McConville F, Moyo NT, et al. Barriers to and strategies for addressing the availability, accessibility, acceptability and quality of the sexual, reproductive, maternal, newborn and adolescent health workforce: addressing the post-2015 agenda. BMC pregnancy and childbirth. 2018;18(1):55.

82. Nair M, Yoshida S, Lambrechts T, Boschi-Pinto C, Bose K, Mason EM, et al. Facilitators and barriers to quality of care in maternal, newborn and child health: a global situational analysis through metareview. BMJ Open. 2014;4(5):e004749.

83. Kasthurirathne SN, Mamlin BW, Purkayastha S, Cullen T. Overcoming the Maternal Care Crisis: How Can Lessons Learnt in Global Health Informatics Address US Maternal Health Outcomes? AMIA Annu Symp Proc. 2018;2017:1034-43.

84. Campbell J, Buchan J, Cometto G, David B, Dussault G, Fogstad H, et al. Human resources for health and universal health coverage: fostering equity and effective coverage. World Health Organization Bulletin of the World Health Organization. 2013;91(11):853-63.

85. Bohren MA, Vogel JP, Hunter EC, Lutsiv O, Makh SK, Souza JP, et al. The Mistreatment of Women during Childbirth in Health Facilities Globally: A Mixed-Methods Systematic Review. PLoS Med. 2015;12(6):e1001847-e.

86. Owili PO, Muga MA, Mendez BR, Chen B. Quality of care in six sub-Saharan Africa countries: a providerbased study on adherence to WHO's antenatal care guideline. International Journal for Quality in Health Care. 2019;31(1):43-8.

\section{Figures}




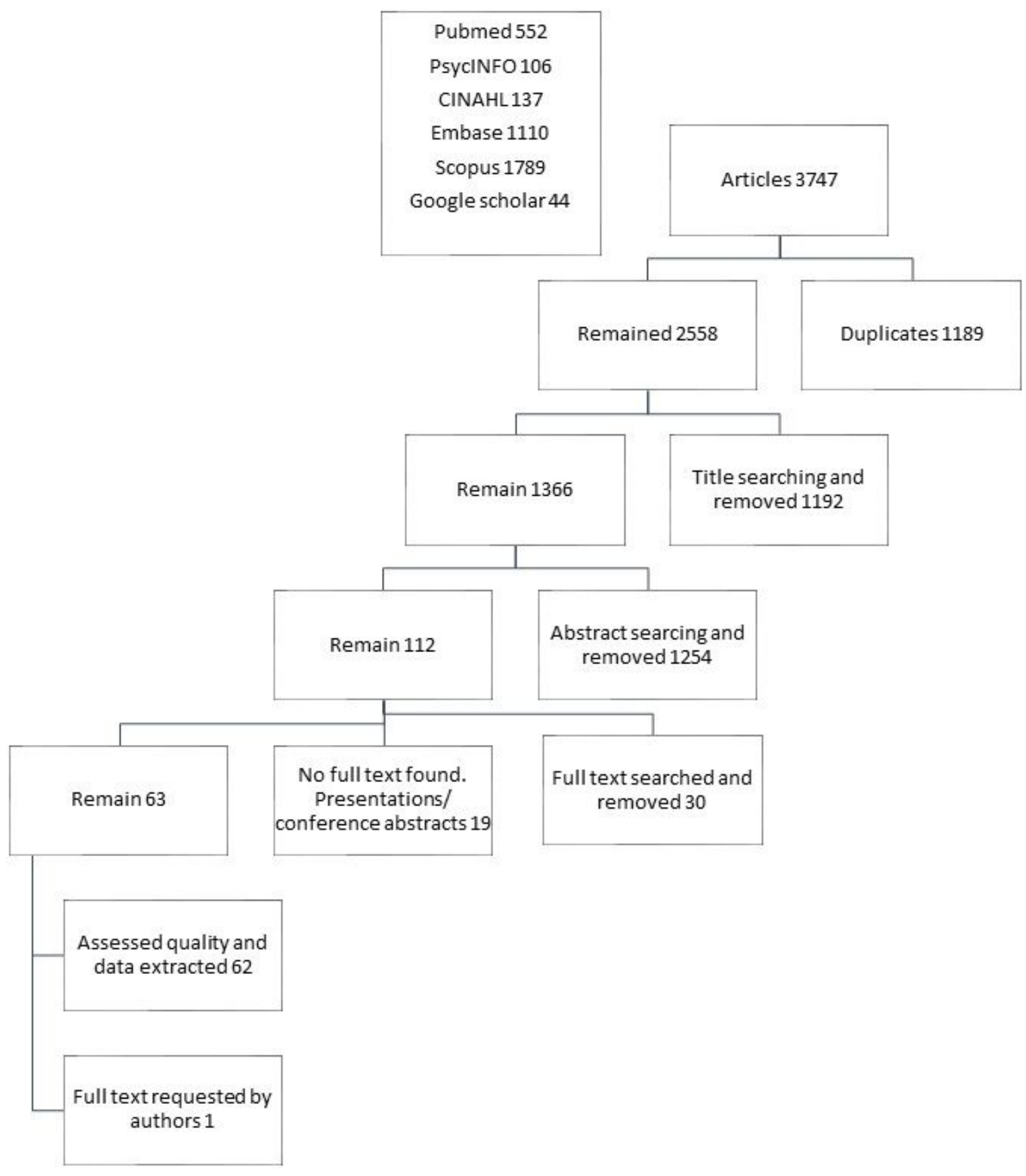

Figure 1

PRISMA flow diagram

\section{Supplementary Files}

This is a list of supplementary files associated with this preprint. Click to download.

- Additionalfile5Summarizedtablesofextracteddta.docx 
- Additionalfile4characteristicsofstudies.docx

- Additionalfile3qualityassessmentchecklist.docx

- Additionalfile2Searchstrategy.docx

- Additionalfile1PRISMAchecklist.doc 